University of Nebraska - Lincoln

DigitalCommons@University of Nebraska - Lincoln

To Improve the Academy

Professional and Organizational Development Network in Higher Education

1998

Academic Morphing: Teaching Assistant to Faculty Member

Kathleen S. Smith

Patricia L. Kalivoda

Follow this and additional works at: https://digitalcommons.unl.edu/podimproveacad

Part of the Higher Education Administration Commons

Smith, Kathleen S. and Kalivoda, Patricia L., "Academic Morphing: Teaching Assistant to Faculty Member" (1998). To Improve the Academy. 417.

https://digitalcommons.unl.edu/podimproveacad/417

This Article is brought to you for free and open access by the Professional and Organizational Development Network in Higher Education at DigitalCommons@University of Nebraska - Lincoln. It has been accepted for inclusion in To Improve the Academy by an authorized administrator of DigitalCommons@University of Nebraska - Lincoln. 
Smith, K. S., \& Kalivoda, P. L. (1998). Academic morphing: Teaching assistant to faculty member. In M. Kaplan (Ed.), To Improve the Academy, Vol. 17 (pp. 85-102). Stillwater, OK: New Forums Press and the Professional and Organizational Development Network in Higher Education. Key Words: Academic preparation, career development, faculty development, future professoriate, graduate students, mentoring, personal development, teaching assistants, time management, training.

\section{Academic Morphing: Teaching Assistant to Faculty Member}

\section{Kathleen S. Smith}

\section{Patricia L. Kalivoda}

The University of Georgia

This paper discusses the process by which graduate teaching assistants (TAs), participating in a longitudinal study, used their graduate TA experience to successfully survive the transition from being a teaching assistant to becoming a faculty member. A theoretical framework is presented that describes how individual characteristics of the TAs worked together with disciplinary, institutional, and departmental forces to shape a set of professional values. These professional values helped to form strategies for success: one set used for securing the first faculty position and the other set used to balance professional roles during the first year as a faculty member. These strategies for success contributed to the socialization process of the TAs in the first year of their faculty positions. The results of this study may help institutions broaden opportunities for graduate student support. 
It is the first three semesters of a faculty career that provide the framework for future success or failure. Early career events offer a complete and predictable picture of how new faculty will thrive. How well both women and men make that transition from being a graduate student to an active faculty member in terms of being immersed in campus life, in being productive, in self-management, and in social management in their discipline is evident even by the third semester on a campus (Boice, 1992). The time frame for this academic morphing from teaching assistant to faculty member is reflected in the third year review process that many institutions use to promote or evaluate new faculty.

The transition from graduate student to faculty member the first year of that three-year span is perhaps the most crucial because it marks a drastic change in circumstance, location, monetary rewards, professional status, family upheaval, and professional challenges. This paper discusses the process by which graduate teaching assistants (TAs), participating in a longitudinal study, used their TA experience to help them successfully manage the first year transition from being a teaching assistant to becoming a faculty member.

\section{Background}

In recent years, educational scholarship in higher education has focused on the pedagogical training of graduate students (Chism, 1987; Lewis, 1993; Nyquist, 1991). Since the concept of scholarship in higher education emphasizes research as well as the pedagogy of the discipline, some graduate programs provide training and experience in discipline-based pedagogy. This not only addresses the public outcry about the quality of instruction at large, research institutions, but also acknowledges the reality that most graduates do not find jobs at research institutions (Western Interstate Commission for Higher Education, 1992). There is, however, little in the literature to document the impact these policies and programs have on the career paths of graduate assistants (Bomotti, 1994), particularly women and minorities. The purpose of this longitudinal study (now in the fourth year) is to track how doctoral students use their graduate experience to make a successful transition into faculty roles. 
This study is built on the work of Baldwin (1990), Kalivoda (1993), Simpson and Smith (1993), Smith (1991), and Smith and Simpson (1992). In particular, the investigators hope to understand how the interplay of personal characteristics like independence, family commitment, and individual goals mesh with environmental factors such as institutional support, departmental support, and the nature of the discipline, to shape the values and strategies of TAs as they move from being a graduate student to being a new faculty member. This transition period-from TA to new faculty member-is crucial to the success or failure of an academic career. Our research began with the questions: How do highly successful TAs take advantage of their graduate experience to prepare for a faculty position? How do their graduate experiences help them through the job search process and the first year as a faculty member?

\section{Research Methods}

The investigators are using a qualitative, multi-case study approach (Merriam, 1988) using the constant comparative method to develop grounded theory as outlined by Glaser and Strauss (1967). The goal of grounded theory research is to generate theory that accounts for a pattern of behavior that is relevant and problematic for those involved (Strauss, 1987). During the first three years of the longitudinal study, data was collected and analyzed from teaching assistants who had or were currently participating in the well established Teaching Assistant Mentor Program (Smith, 1993) coordinated through the Office of Instructional Support and Development at The University of Georgia. Participants in this program, now in its ninth year, are experienced teaching assistants who have been recognized at the institutional level for their outstanding teaching. Each year, ten to fifteen TAs are selected from a variety of disciplines to serve as TA Mentors. These TA Mentors participate in a year-long mentoring experience that includes group discussions on teaching, individual mentoring by faculty members, and mentoring by and for TA peers. In addition, past and present TA Mentors are able to participate in a private listserv discussion on teaching. We felt this prolonged engage- 
ment with our research subjects was needed to allow us the time to establish a credible data base.

\section{Data Analysis and Interpretation Techniques}

In 1993, the first year of the study, we began collecting data about the graduate teaching assistant experience using purposeful sampling (Bogdan \& Biklen, 1982 ) from 35 past and present TA Mentors. By focusing on how these outstanding TAs took advantage of their TA experience to manage the transition into faculty positions, we hope to learn more about the graduate student strategies and the kinds of support that promote a successful transition from TA to faculty member. At this point in the study, data collection and analysis has occurred simultaneously over a four year period and includes 56 participants.

During Phase I of the study, the investigators interview (Spradley, 1979) and observe (Spradley, 1980) present and past graduate teaching assistant participants of the TA Mentor Program. Data from interviews, observations, and group discussions on teaching, and from the listserv, TAMENTOR, are transcribed and entered into a computerized data-base manager (Filemaker Pro, 1990). These data are coded and categorized to identify patterns and roles which contribute to the TA experience.

Phase II of the study began in 1994 as members of the first cohort of the TA Mentor study moved into their first faculty positions and began to use their graduate experience as the basis for a career. Data from Phase II participants comes from TAMENTOR listserv discussions, mailed questionnaires, and individual interviews. The focus of the Phase II data collection is to determine what aspects of the graduate experience helped participants, from a variety of backgrounds, successfully move into full-time, tenure-track careers. Through the TAMENTOR listserv discussion we are able to compare perceptions and strategies and to verify with the participants our understanding of the data. Integrative diagrams were used from the early stages of the data collection to visualize and conceptualize data. The function of these operational diagrams was to pull together what the researchers were understanding, to stimulate further investigation, to fill in the 
gaps, and to choose the next issue to investigate. Figure 1 depicts our current understanding of the transition process experienced by the participants in this study.

This is a multi-case longitudinal study which seeks to build abstractions across cases. For this paper, we focus on the representative experiences of three TAs in the study which illustrate the patterns of behavior more successful TAs use in making the transition from graduate assistant to faculty member. Although these TAs were quite diverse, each individual case also represents a compelling interpretation of how a graduate student might benefit from their graduate experience in making a smooth transition the first year of a faculty career. Weiland (1994) in Writing the Academic Life: Faculty Careers in Narrative Perspective states that "a single career is worth very specific attention and the hope that it is not so isolated from the experience of colleagues that its social meanings will be lost"( p. 399).

\section{Findings}

\section{Background Variables: Individual Characteristics}

The three TAs described in this paper we shall call Carol, Andrew and Melinda. Like many doctoral level students at our institution and in the TA Mentor Program, they had not moved straight from college to graduate school. Rather, they had stopped to have families and to experiment with other careers before gravitating toward academic careers. By the time these TAs entered their graduate programs, they had established clear goals about what they did -and did not want - to do with their lives. Although their personal backgrounds and goals were quite different, they had some similarities. For example, each held a strong commitment to teaching. The well-defined goal of "Making teaching a priority," while being socialized in the culture of a Research I institution was also a characteristic of the other TA Mentors in the study.

This theme of having clearly defined goals and taking a proactive approach to meeting those goals, we categorized as a background variable and coded as an "entrepreneurial approach to life," a phrase they used to describe themselves (Figure 1). As a group, the TA 
Mentors are aggressively proactive and highly selective in choosing experiences which complement their goals.

Although these three TAs had clear career goals, many of their professional decisions were shaped by the realities of their personal lives. This is a background variable shared by many of the participants in the study. Andrew was able to quit his high school teaching job and return to graduate school because his wife had a good job. Carol was delaying the job search to accommodate a child finishing high school. All three intended to explore job locations based on the needs of family members. Andrew wanted a position and a location which would allow his wife to stay home with a new baby daughter. Carol married during her year as a TA Mentor so needed to consider her spouse's professional needs as she prepared for the job search, and Melinda's husband needed to find a job teaching high school.

\section{Intervening Variables: Disciplinary, Institutional, and Departmental}

A number of disciplinary, institutional, and departmental forces also influenced career choices and helped to develop professional values (Figure 1). Two disciplinary forces appeared to influence the career goals of the TAs in this study: the job market and teaching opportunities. The job market was highly dependent on their discipline. Andrew acknowledged that the job market in English was not terrific for "white guys who studied dead white guys." Similarly, despite her outstanding credentials, Melinda expressed uncertainty about her marketability in the job market for doctorates of Economics. In contrast, disciplinary forces worked in Carol's favor. Graduates in her area of Journalism were in demand, so she felt very confident in considering institutions that meshed with her career goals and accommodated her family's needs. Knowing the job market in each of their disciplines helped these TAs to focus on graduate experiences that would make them more marketable.

Disciplinary forces combined with institutional policy also played important roles in providing these graduate students with teaching opportunities. With lower division requirements and large introductory sections in their disciplines, all three TAs were teachers-of-record 
for a number of class sections during their graduate programs. As graduate students, they had the opportunity to develop as classroom teachers because they had full responsibility for teaching certain courses. A variety of teaching experiences, both in subject content and class size, also contributed to their professional development. Toward the end of their doctoral programs, Carol and Melinda were teachersof-record for large sections of more than 100 students.

During their graduate years, these TAs were exposed to institutional factors which profoundly influenced their careers. For example, institutional policy requires any graduate student with a TA designation to be assigned teaching duties and receive formal support for professional teaching development. The institution's central program also provides opportunities for workshops, faculty mentoring, and individual consultation. Melinda sought out and participated in the institution's Teaching Improvement Process-a cross-disciplinary program that involves senior faculty interested in helping TAs develop their pedagogy. This is an example of how a TA's "entrepreneurial approach" meshed with an institution, enabling structure to allow professional growth. This trait of taking advantage of opportunities offered by the institution was characteristic of many of the participants in the study.

In the past several years, the rapidly increasing student body also increased the importance of the teaching assistantship to the instructional mission of the university and provided numerous opportunities to teach. Being at a Research I institution, which includes teaching assistants as an essential part of the instructional community, also enabled these graduate students to document their teaching effectiveness through class evaluations and the opportunity to win various teaching awards. Many graduate students do not have this professional development opportunity and a mechanism for documenting their teaching success.

The nature of the department also shaped these graduate students' professional development in several ways. Andrew was considered one of the finest doctoral research students by his very research-oriented department. He considered access to a research library and departmental resources instrumental in his professional preparation. On the other hand, he felt that his department was slowly developing 
a commitment to teaching. His department did support the university policy that new TAs participate in a Fall Workshop for Graduate Teaching Assistants and a year-long teaching support program in the department.

Carol and Melinda were in much smaller departments that also had strong research support but little formal support for teaching. Therefore, they were required by university policy to take the institution's seminar on teaching. These TAs also used their "entrepreneurial approach to life" to seek out teaching support and to maximize their professional experiences while adapting to the nature of their discipline, institution, and department. Their proactive approach to taking advantage of the TA experience gave them a solid base on which to pursue a faculty position.

\section{Enabling Variables: Professional Values}

Individual characteristics and environmental forces worked together to shape or strengthen the professional values of these TAs. We coded this process as "Enabling Variables" and defined it as the opportunities offered by the institution combined with a TA's willingness to take advantage of these opportunities. Three values were identified in this stage of the investigation: self-improvement as a way of life, a commitment to teaching, and generosity of ideas.

With a clear sense of their desired career path, these TAs persistently sought out opportunities for growth. Melinda developed mentoring relationships with faculty members outside of her department. Carol negotiated to teach the same large class repeatedly in her graduate program in order to perfect her teaching while allowing time for research. Although they perceived their academic departments as being narrowly focused on research, each of them chose to pursue teaching-related activities throughout their graduate programs. This interest in teaching excellence served them well as they moved into the job search. As a TA Mentor they developed a teaching portfolio. Being able to document their teaching expertise was influential in the job search and was credited with getting them interviews. Formal teaching recognition also identified them early in their careers as excellent teachers. As participants in the TA Mentor Program, these 
TAs arranged their hectic schedules to attend sessions and mentor peers in the department. Making the discussion of teaching public and sharing their ideas about teaching followed them into their new positions as they sought out colleagues interested in teaching and continued to share ideas via the TA Mentor discussion list.

\section{Strategies for Success: Securing a Faculty Position}

All three TAs were successful in securing faculty positions the year following their participation in the TA Mentor Program. Strategies they found useful in the job search included: (1) clarify what type of institution will fit your career goals; (2) develop interview skills; (3) seek an institution where faculty you admire are employed; and (4) establish your credentials as an outstanding teacher.

While acknowledging market-driven considerations in their job search, each of these TAs emphasized the importance of knowing what kind of institution would make them happy. Carol felt strongly that she wanted to remain at a research institution. Melinda wanted an institution that placed an emphasis on teaching, but with opportunities to continue her research. Andrew hoped to become a faculty member at a smaller college or university with a teaching orientation.

Carol expressed a sentiment that ran through all three TAs' transition to becoming faculty members. She said, "Remember that your career exists, to an extent, independent of any institution." Earlier we characterized these TAs as having clearly defined professional goals. As they prepared, looked for, and found their first faculty positions, they seemed to have a vision of how they wanted their careers to develop. Although Carol was a dedicated teacher, she chose a research institution because she thought it would be easier to manage her career choices from that kind of an institution. Melinda and Andrew accepted positions at teaching-oriented institutions because these schools reflected their dedication to teaching, yet both of them continued to work on research and to give conference papers. Since the job market in English was so difficult, Andrew realistically saw his career path as "get a job, get a better job, get an even better job and repeat as necessary." This entrepreneurial approach to managing career choices independent of the goals of the institution was a strategy 
these TAs and other TA Mentors developed in their graduate program and into their early years as faculty members. This approach appeared to ease the transition from a research I institution to other types of institutions because as new faculty these TAs responded to the orientation of their new institutions while honoring aspects of their careers they wanted to continue to develop.

Upon receiving her doctorate, Melinda moved from a large public research institution to a smaller, private, teaching-oriented institution. In her first faculty position, she initially experienced some uncertainty because she found herself wondering if she would stack up against other faculty in her new department-a department that valued teaching. Nevertheless, she immediately threw herself into teaching by trying to incorporate new teaching techniques into her repertoire. She felt her confidence to tackle new pedagogy came from her experience as a teacher-of-record for large introductory courses of more than 100 students during her graduate years. With a variety of graduate school experiences to bolster her courage, she forged ahead. She also continued to discuss teaching issues and faculty roles with present and former TA Mentors on the TA Mentor listserv. In discussions with other TA Mentors, Melinda recommended networking across campus for opportunities to develop one's teaching, especially if the academic department did not offer many opportunities.

\section{Enabling Variables: Professional Role Balance in the First Faculty Position}

With the job search behind them, Andrew, Carol, and Melinda continue to stay involved in the TA Mentor Program by contributing to discussions on the TA Mentor listserv. In reflecting on aspects of their TA experience that enabled them to successfully survive the job-search process and to be effective as a new faculty member, they made a number of important recommendations to their fellow TA Mentors. At this point in our study, a pattern of behavior has emerged which seems to have enabled these TAs to make the transition from graduate student to new faculty member at diverse institutions. This pattern of behavior was reflected in suggestions from the new faculty members to (1) develop a cross-campus perspective, (2) avoid depart- 
mental politics, (3) be entrepreneurial in career development, (4) develop time management strategies, (5) seek mentoring relationships, and (6) examine teaching strategies.

Unlike many of their peers, the TA Mentors experience a crosscampus perspective of campus life during their graduate program. The TA Mentors share departmental degree requirements, balancing research and teaching expectations and insights about departmental cultures. When they move into their first faculty positions they have an impression of the dynamics of a variety of departments and often continue to value opportunities to participate in activities beyond their department.

With a cross-campus perspective of departmental cultures, these TAs encouraged their cohorts with comments such as "During your first year, listen more than you speak [because] there is no way to know the history of the department and the relationships among the other faculty." Avoiding involvement in the politics of the department the first year worked in their favor as they built departmental relationships and established their departmental roles.

Nevertheless, all three TAs identified time management and role balance as the most serious challenges of the first-year faculty member. Although they had successfully handled complicated time commitments as graduate students, they continued to struggle with professional role balance. Carol acknowledged that it was easy to procrastinate without the imposed deadlines of graduate school. She stressed the importance of clarifying before accepting a faculty position the activities and roles expected and then deciding how and if you will be able to manage your priorities within that framework. Melinda used her graduate school strategy of blocking out entire days for research rather than trying to do research only after completing teaching preparations and office hours. Andrew threw himself into teaching three classes and acting in a play the first quarter he arrived on campus leaving himself with very little free time. Although none of these TAs felt they had yet achieved a complete balance between their professional and personal lives, using some of the time management strategies they had developed during their graduate programs was a strategy that helped them at least manage their first year as faculty members. A TA Mentor session which focused on the business 
world model of time management gave each of these TAs an awareness of how to set priorities. Another session on faculty vitality made them acutely aware of protecting at least some personal time during their first year transition. Andrew knew by October that teaching three classes a quarter would not leave him the personal time he needed, so he began to plan his next step strategy that included guarding his personal time and sending out resumes to other institutions.

Having experienced the concept of mentoring as graduate students, these TAs sought out and nurtured mentoring relationships as new faculty members. This included colleagues in their departments and continued support from their TA Mentor peers via their TA Mentor listserv discussions. Carol actively sought and found a department where she admired the faculty and considered individuals as possible mentors. The mentoring relationships Carol developed in her first faculty position served her well when a class project meant to inform her students of ethical practices in the field backfired and focused national attention on the activity as unethical in and of itself. Having discussed the project thoroughly with her departmental colleagues, they were firmly behind her professional decision and she weathered the national criticism. Without the support of her department, this kind of criticism at the beginning of an academic career could well have proved a disaster.

An unanticipated challenge for two of these TAs at their new institutions was accommodating a different type of student in terms of background and expectations. Melinda was surprised at how much more demanding, yet less motivated students at her more selective private institution were compared to the students she had at a public state school. Andrew was challenged to find new strategies that would help students "who somehow got a high school diploma without the high school education." Nevertheless, these new faculty members found working with young people worth the challenge and tried hard to develop effective classroom and office hour strategies. Armed with confidence in their ability to approach these situations creatively based on their graduate school successes, they developed new strategies to accommodate diverse students. Melinda developed more interactive lecture practices to draw in her less motivated students. Andrew found 
it necessary to provide more developmental support for students in his classes.

\section{Outcome Variables: Vitality}

From a personal and institutional perspective, there is a tremendous investment in preparing a graduate student for a faculty position. Long-term involvement and commitment to the field is the payoff for the individual as well as the institution for this investment. Early career events and practices contribute to maintaining vitality throughout an academic career (Kalivoda, 1993). With a clear sense of their desired career path, these TAs developed long-term goals during their graduate programs. Although their first year in a faculty position presented many challenges, they entered their second year as faculty members with a renewed commitment to and perhaps a more realistic view of managing their time to achieve some of their goals. This ability to monitor and adjust strategies to achieve goals was a strategy we observed during the graduate years and one which seemed to help them during the first year as faculty members. Since Andrew knew very early in his first faculty position that he would need to move on to a different type of institution to reach his goals, he immediately began searching for a more suitable position. He felt that working at the two-year college was professionally very valuable and "...has been a real boost to my c.v..." in a very difficult job market. At the end of his first year as a faculty member, Andrew was very pleased to find a four-year institution that wanted a medievalist and felt he had found "Just the place I wanted when I began grad school."

As these TAs began their second year as faculty, they had successfully completed a critical year in their careers. Perhaps a measure of their effectiveness was acknowledging that they had even developed strategies for rewarding themselves. For example, Melinda took a short vacation, Andrew blocked out personal time for his new baby and his first house, and Carol took advantage of the three-month summer break to be away from her campus address and to focus on writing and other interests. Developing and maintaining strategies for self-renewal was an important concept they had discussed at a TA Mentor session with senior faculty identified as maintaining vitality 
over a very long career (Kalivoda, 1993). During their graduate program, TA Mentors actively think about their personal goals and ways to maintain enthusiasm and reward themselves. These TAs appeared to benefit from the strategies they had developed as TAs to maintain vitality.

\section{Discussion}

We began this study looking for a pattern of behavior and support that would contribute to a successful transition into the first year as a new faculty member. The TA Mentors participating in the study have, as a group, been highly successful in making this transition. The three TAs we have described in this paper demonstrate this successful transition to being immersed in departmental and campus life. They have become productive scholars and have managed their professional lives while honoring their personal priorities. We feel that their successful transition was due in large part to strong foundations built during the graduate experience. Even though these TAs were not from departments that strongly valued teaching, many opportunities for pedagogical development and formal recognition were available to them outside of their departments. They also were given many opportunities to teach because their disciplines offered numerous sections of introductory or required courses. The combination of an entrepreneurial approach to their careers with discipline and institutional needs and policies helped these $T A s$ to develop confidence in responsibilities that reflected future faculty roles.

\section{Conclusions and Implications}

We believe that extending these graduate school opportunities to a wider group of students may better prepare future faculty members for becoming immersed in campus life, in being productive scholars, and in managing their career development. We have moved to expand the impact of the TA Mentor Program on this campus by providing former TA Mentors assistantships to share what they have learned with new TAs in their academic departments. In some cases their departmental leadership has changed the teaching culture of the department by simply making teaching public. These efforts appear to 
provide a diverse population of graduate assistants and new faculty members increased opportunities for success in assuming their professional roles.

This study has also shown that TAs who successfully move into faculty careers begin the academic morphing process early in a graduate program by aggressively taking advantage of a variety of graduate school experiences which reflect faculty roles. We will continue to follow Melinda, Andrew, and Carol and the other teaching assistants and new faculty members who are participating in the longitudinal study for several more years. As the participants complete the academic morphing process from graduate teaching assistant to faculty member, we hope to broaden our understanding of the graduate school experience and the impact it has on fostering a successful transition into faculty roles.

\section{References}

Association of American Colleges (1985). Integrity in the college curriculum: A report to the academic community. Washington, DC: Association of American Colleges.

Baldwin, R. G. (1990). Faculty career stages and implications for professional development. In J. H. Schuster, D. W. Wheeler, \& Associates (Eds.), Enhancing faculty careers: Strategies for development and renewal (pp. 20-40). San Francisco: JosseyBass.

Bogdan, R. C., \& Biklen, S. K. (1982). Qualitative research for education: An introduction to theory and methods. Boston, MA: Allyn and Bacon.

Boice, R. (1992). The new faculty member: Supporting and fostering professional development. San Francisco: Jossey-Bass.

Bomotti, S. S. (1994). Teaching assistant attitude toward college teaching. The Review of Higher Education, 17(4), 371-393.

Chism, N, V. (Ed.). (1987). Institutional responsibilities and responses in the employment and education of teaching assistants. Columbus, $\mathrm{OH}$ : The Ohio State University, Center for Teaching Excellence.

Chism, N. V. (1989, November). Supervisors and TAs on the teaching help they give and receive. Paper presented at the Second National Conference on the Training and Employment of Teaching Assistants, Seattle, WA.

Filemaker Pro. (1990). Santa Clara, CA: Claris Corporation.

Glaser, B., \& Strauss, A. L. (1967). The discovery of grounded theory: Strategies for qualitative research. Chicago: Aldine.

Kalivoda, P. (1993). An investigation of factors that influence faculty vitality at a large, public research university. Unpublished Ed.D. dissertation, University of Georgia. 
Lewis, K. G. (1993). The TA experience: Preparing for multiple roles. Stillwater, OK: New Forums Press.

Merriam, S. B. (1988). Case study research in education: A qualitative approach. San Francisco: Jossey-Bass.

Nyquist, J. D., Abbott, R. D., \& Wulff, D. H. (Eds.). (1991). Preparing the professorate of tomorrow to teach: Selected readings in TA training. Dubuque, IA: Kendall/Hunt.

Simpson R. D., \& Smith K. S. (1993). Validating teaching competencies for graduate teaching assistants: A national study using the delphi method. Innovative Higher Education, 18(2), 133-146.

Smith, K. S. (1991). The development of international teaching assistants as successful undergraduate instructors. Unpublished Ed.D. dissertation, University of Georgia.

Smith, K. S. (1993). Investment in teaching: Mentoring for teaching assistants. In K. G. Lewis (Ed.), The TA experience: Preparing for multiple roles (pp. 260-265). Stillwater, OK: New Forums Press.

Smith, K. S. (1993). Managing and mentoring graduate teaching assistants at The University of Georgia. In T. A. Heenan, \& M. Helgesen (Eds.), Proceedings of the fourth national conference on the training and employment of graduate teaching assistants (pp. 101-106). Urbana-Champaign, IL: University of Illinois.

Smith, K. S., \& Simpson, R. D. (1992). Becoming successful as an international teaching assistant. The Review of Higher Education, 16(4), 483-497.

Smith, K. S. (1993). Investment in teaching: Mentoring for teaching assistants. The Journal of Graduate Teaching Assistant Development, 1(1), 43-48.

Spradley, J. P. (1979). The ethnographic interview. Chicago: Holt, Rinehart and Winston.

Spradley, J. P. (1980). Participant observation. Chicago: Holt, Rinehart and Winston.

Strauss, A. L. (1987). Qualitative analysis for social scientists. Cambridge, MA: Cambridge University Press.

Weiland, S. (1994). Writing the academicl life: Faculty careers in narrative perspective. The Review of Higher Education, 17(4), 395-422.

Western Interstate Commission for Higher Education (1992). Bringing into focus the factors affecting faculty supply and demand: A primer for higher education and state policy makers. Boulder, $\mathrm{CO}$.

Contact:

Kathleen Smith

Office of Instructional Support and Development

Instructional Plaza - North

The University of Georgia

Athens, GA 30603-3016

(706) 542-1355

(706) 542-6587 FAX

ktsmith@uga.cc.uga.edu 
Kathleen S. Smith is Academic Professional Faculty at The University of Georgia Office of Instructional Support and Development. She holds graduate degrees in Language Education and Higher Education from The University of Georgia and has served as Administrative Coordinator and Acting Head of the University of Georgia's intensive English Program. Currently, she is TA Program and International Fellows Program coordinator at The University of Georgia. Her research and teaching has focused on the development and administrative support of teaching assistants with a special focus on international teaching assistants.

Patricia Kalivoda is Coordinator of Faculty Development in the Office of Instructional Support and Development at the University of Georgia. She holds a B.S.Ed., M.B.A., and Ed.D. in Higher Education from The University of Georgia. Dr. Kalivoda's scholarship centers on faculty career development and faculty vitality issues. 


\section{FIGURE 1}

\section{Background} Variables

Intervening Variables

Enabling Variables

Outcome Variables

\section{A TA's Successful Transition into a Faculty Career}

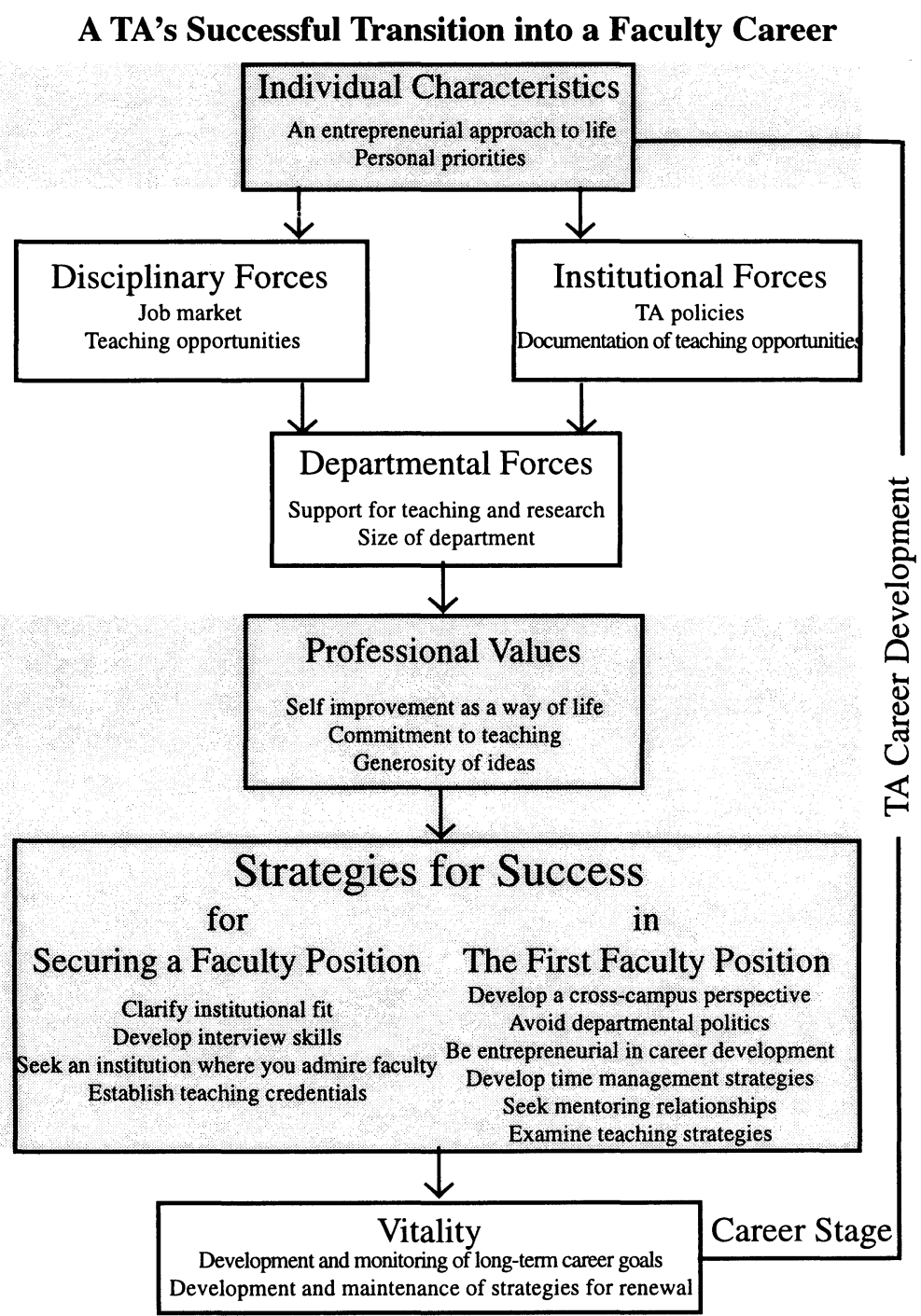

